\title{
Towards an analysis of the causative/non-causative alternation in Udmurt
}

\author{
Orsolya Tánczos \\ Research Institute for Linguistics, \\ Hungarian Academy of Sciences, Budapest \\ orsolyatan@gmail.com
}

\begin{abstract}
The paper studies the causative/non-causative alternation in Udmurt. I propose an analysis based on Distributed Morphology (Marantz 1984; 1997): I suggest that the causative and non-causative variants of the alternation in Udmurt are derived from roots and not from each other. The difference in the argument structure of the variants is due to the fact that as with verbs marked with the productive causative morpheme, the structure of causative verbs also always contains a Cause head (in the sense of Pylkkänen 2002; 2008). Non-causative verbs, on the other hand, have only a Voice head (in the sense of Kratzer 1996).
\end{abstract}

Keywords: causative/non-causative alternation; Udmurt; syntactic derivation; Distributed Morphology; Voice head

\section{Introduction}

The present paper deals with the causative/non-causative alternation in the Udmurt language. ${ }^{1}$ Its aim is to present new empirical data and to propose a syntactic analysis of the alternation couched in the framework of Distributed Morphology (see Marantz 1984; 1997, and Arad 2005). I will claim that the transitive/intransitive verbs taking part in the alternation are not derived from each other, but they are both formed from roots, in the sense of Alexiadou et al. (2006).

It will be shown that the causative and non-causative variants have different syntactic structures: the former contain a Cause head, while the

${ }^{1}$ Udmurt is a minority language from the Permic branch of the Uralic language family, spoken in the Russian Federation. According to the 2002 census, the number of the native speakers is ca. 650000 and the Udmurt population became bilingual in the 20th century (Salánki 2007). Udmurt is a head-final language and it is strongly agglutinative with a very transparent morphology. 
latter lack the Cause head and contain only Voice in the sense of Pylkkänen $(2002 ; 2008)^{2}$ and Kratzer (1994).

The paper is organized as follows. Section 2 outlines the causative/noncausative alternation in Udmurt, listing the different types of alternations (2.1) and determining the argument structure of causative and noncausative verbs (2.2). Section 3 deals with two important valence-change markers in Udmurt, both of which have an important role in the alternation. Section 4 focuses on the difference between passive and non-causative constructions. Section 5 zooms in on the main properties of the alternation (e.g., causer, agentivity) and the inner structure of the alternating verbs. Finally, section 6 concludes the paper.

\section{Overview of the causative/non-causative alternation in Udmurt}

\subsection{The data}

The typological classification of inner causation in Udmurt is still an understudied area of Udmurt syntax. There are two not very detailed studies that could be taken as a starting point for the investigation: Haspelmath (1993) and Kozmács (2004). However, these works only list the types of the alternation without providing a deeper explanation for the phenomena at hand.

In his typological work on the causative/inchoative alternation, Haspelmath (1993) examined 31 languages from different language families. The Uralic family is represented by the Hungarian, Finnish and Udmurt languages. His typological classification follows Nedyalkov \& Silnitsky $(1973)^{3}$ and it is based on 20 alternating verb-pairs in each language, therefore it contains several errors. These mistakes were corrected by Kozmács (2004). The categorization of the alternation presented below is based on Kozmács (2004).

${ }^{2}$ For a detailed discussion of CauseP and VoiceP, see section 5.

${ }^{3}$ Nedyalkov and Silnitsky (1973) examined the causative alternation in Russian and found the following groups in the language:

(i) a. smejat'sja 'laugh' smeshit 'amuse, make laugh' Anticausative

b. kipet' 'boil, come to kipjatit' 'boil, bring to a boil' Causative a boil'

c. goret' 'burn' zhech' 'burn, ignite' Suppletive

d. perelomit'sja 'break, perelomit' 'break in two' Equipollent get broken in two' 


\subsubsection{Causative alternation}

In Nedyalkov and Silnitsky's (1973) classification, in the causative alternation the non-causative verb is the basic form and the causative is marked by a suffix.

(1) a. Pinaljos sajka-zy. ${ }^{4}$

child.PL.NOM wake.up-PAST.3PL

'The children woke up.'

b. Anaj pinaljoszy sajka-t-iz.

mother.NOM child.PL.ACC wake.up-CAUS-PAST.3SG

'The mother woke up the children.'

In (1a) the non-causative verb sajkazy 'to wake up' contains only a root (in the sense of Marantz 1984) and a null affix responsible for the verbal category (see Arad 2005). ${ }^{5}$

In (1b) the verb also contains the $-t$ - inner causative affix. This morpheme is historically related to the productive causative marker $-t$ - as in (2) and it is also the verbalizer as in (3). I come back to this issue in section 3 .

(2) a. Sasha gozhtetez gozht-iz.

Sasha.NOM letter.ACC write-PAST.3SG

'Sasha wrote the letter.'

b. Sasha Mashajez gozhtetez gozhte-t-iz. ${ }^{6}$

Sasha.NOM Masha.ACC letter.ACC write-CAUS-PAST.3SG

'Sasha made Masha write the letter.'

${ }^{4}$ The data in this paper were collected during my fieldwork in three distinct periods between 2012-2013. The informants are all Udmurt-dominant native speakers between 20 and 50 years of age, living in the territory of the Udmurt Republic.

Abbreviations: $\mathrm{ABL}=$ ablative, $\mathrm{ACC}=$ accusative, $\mathrm{CAUS}=$ causative affix, $\mathrm{DET}=$ determinate suffix, $\mathrm{ERG}=$ ergative suffix, $\mathrm{FUT}=$ future tense, INESS $=$ inessive, $\mathrm{INSTR}=$ instrumental, $\mathrm{NOM}=$ nominative, $\mathrm{PASS}=$ passive, $\mathrm{PAST}=$ past tense, $\mathrm{PL}=$ plural, $\mathrm{PRES}=$ present tense, $\mathrm{PX}=$ possessive suffix, $\mathrm{REF}=$ reflexive affix, $\mathrm{SG}=$ singular, VERB $=$ verbalizer.

${ }^{5}$ In Distributed Morphology words with a lexical category N, V and A are created in a way that a lexical category head $\mathrm{n} / \mathrm{v} / \mathrm{a}$ is attached to the root (Arad 2005).

(i)

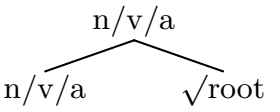

The morphological realization may differ from language to language and in some languages the verb-creating morphology may be a phonologically null suffix (Arad 2005). 
(3) a. Sasha vamysh ljog-iz.

Sasha.NOM step.NOM make-PAST.3SG

'Sasha took a step.'

b. Sasha vamysh-t-iz.

Sasha.NOM take.a.step-VERB-PAST.3SG

'Sasha took a step.'

\subsubsection{Anticausative alternation}

Unlike in the causative alternation, in the anticausative alternation the causative verb is the basic form and the non-causative is marked by a suffix.

(4) a. Vaza pyly-s'k-iz.

vase.NOM break-ERG-PAST.3SG

'The vase broke'

b. Sasha vazajez pyl-iz.

Sasha.NOM vase.ACC break-PAST.3SG

'Sasha broke the vase.'

As shown in (4a), the non-causative verb is marked by the $-s^{\prime} k$ - morpheme. Unlike in (1b), the causative verb has only a phonologically null verbal category marker in the sense of Arad (2005) and no overt causative suffix appears. ${ }^{7}$

The functions of the morpheme $-s^{\prime} k$ - will be discussed in section 3 .

\subsubsection{Labile alternation}

In the so-called labile alternation, the same verb is used both in the noncausative and in the causative interpretation.

6 Transitive based causatives yield a double-object argument structure.

(i) Masha Sasha-jez kniga-jez lydzhy-t-iz.

Masha.NOM Sasha-ACC book-ACC read-CAUS-PAST.3SG

'Masha made Sasha read the book.'

This is a crucial property of the morphologically marked causative constructions in Udmurt, since Udmurt is not a real double object language; nonderived verbs, even ditransitive verbs, cannot assign two ACC cases. For a more detailed discussion of this topic, see Tánczos (2013).

${ }^{7}$ See section 5 for the syntactic analysis of the verbs. 
(5) a. Urok kut-s'k-iz.

class.NOM begin-ERG-PAST.3SG

'The class began.'

b. Dyshetis' urokez kut-s'k-iz.

teacher.NOM class.ACC begin-ERG-PAST.3SG

'The teacher started the class.'

It is important to note that in the labile alternation both verbs contain a suffix (either the morpheme $-s^{\prime} k$ - or the morpheme $-t$-).

\subsubsection{Equipollent alternation}

In the equipollent alternation, both the causative and the non-causative forms are derived from the same stem. The stem expresses the lexical meaning, and the alternation is signalled by means of different suffixes.

(6) a. Kar umoj azyn-s'k-e.

city.NOM good develop-ERG-PRES.3SG

'The city develops well.'

b. Kivaltis' programmajez azyn-t-iz.

director.NOM program.ACC develop-CAUS-PAST.3SG

'The director developed the program.'

In (6), both the non-causative and the causative verbs are derived from the nominal azyn- 'result' by attaching suffixes to the nominal root.

\subsubsection{Suppletive alternation}

In the suppletive alternation, both variants have different verb roots and neither of them contains the causative or anticausative marker:

(7) a. Sasha kul-iz.

Sasha.NOM die-PAST.3SG

'Sasha died.'

b. Sasha Mashajez vyj-iz.

Sasha.NOM Masha.ACC kill-PAST.3SG

'Sasha killed Masha.'

Given that there is no syntactic relation between the suppletive verb pairs, I do not consider them to instantiate a type of causative/non-causative alternation. This contrasts with the traditional view of these pairs. 


\subsection{The argument structures of variants}

The argument structure of the non-causative variants always contains a patient and lacks an agent or a causer thematic role. The argument structure of the causative variants, on the other hand, contains both the agent/causer and the patient/theme arguments. This is in line with cross-linguistic observations about the causative/non-causative alternation.

\subsubsection{Non-causative verbs}

The most common property of the non-causative verbs presented in section 2.1 is that they all lack an agent argument in their structure (see, for instance, example (7a) in which the only argument of the verb is the theme, Sasha). Although the causer argument can appear in the structure and it can be either (i) a non-agent or (ii) a causing event, an agent causer is not acceptable. The verbs differ in the way in which the causer is encoded in their argument structure.

1. Non-agentive causer. Non-agentive causers are encoded in the argument structure in two ways: either by the ABL case marker -lesh or by the postposition seren 'by'.

(8) a. Pinaljos gudyrjaskem-lesh sajka-zy.

child.PL.NOM thunder-ABL wake.up-PAST.3SG

'The chidren were woken up by the thunder.'

(Lit.: 'The children woke up from the thunder.')

b. Pyzh vyj-iz uragan seren.

boat.NOM sink-PAST.3SG storm.NOM by

'The boat was sunk by the storm.'

(Lit.: 'The boat sunk by the storm.')

c. Vaza pyli-s'k-iz zemljatresenyije seren.

vase.NOM break-ERG-PAST.3SG draft.NOM by

'The vase was broken by the draft.'

(Lit.: 'The vase broke by the draft.')

d. Ös ushti-s'k-iz töl-lesh.

door.NOM open-ERG-PAST.3SG wind-ABL

'The door was closed by the wind.'

(Lit.: 'The door closed from the wind.')

e. Ty kynm-iz kezhyt lyem-lesh.

lake.NOM freeze-PAST.3SG cold be.PART-ABL

'The lake was frozen by the cold.'

(Lit.: 'The lake froze from the cold.') 
As shown by the examples above, the causer argument can appear in the structure regardless of the type of the non-causative verb.

2. Causing event. In some languages (e.g., Greek or German) non-agentive causers and causing events are encoded with different suffixes or prepositions. In Udmurt, however, causing events are encoded in the same way as non-agentive causers, i.e., by ABL case or by the postposition seren 'by':

(9)

a. Pinaljos sajka-zy anaj-atajlen kopaskemzy-lesh.

child.PL.NOM wake.up-PAST.3SG mother-father.GEN fight-ABL

'The children were woken up by the fight of the parents.'

(Lit.: 'The children woke up from the fight of the parents.')

b. Pyzh vyj-iz pydesys' pashas'kem seren.

boat.NOM sink-PAST.3SG bottom hole.NOM by

'The boat was sunk by the hole in the bottom of the boat.'

(Lit.: 'The boat sank by the hole in the bottom of the boat.')

c. Vaza pyli-s'k-iz pinaljos byzhylem seren.

vase.NOM break-ERG-PAST.3SG child.PL.NOM run by

'The vase was broken by the running of the children.'

(Lit.: 'The vase broke by the running of the children.')

d. Ös ushkti-s'k-iz skvoznyak-lesh.

door.NOM open-ERG-PAST.3SG draft-ABL

'The door was opened by the draft.'

(Lit.: 'The door opened by the draft.')

e. Ty kynm-iz omyr kezhitskem-lesh.

lake.NOM freeze-PAST.3SG air.NOM cold.PART-ABL

'The lake was frozen by the cold of the air.'

(Lit.: 'The lake froze by the cold of the air.')

As with non-agentive causes, causing events also appear with all types of non-causative verbs. This is not surprising since there seems to be no syntactic difference between the non-agentive causer and causing event in Udmurt.

3. Agent causer. As will be shown in section 4, passives and non-causative constructions differ in their agentivity. Passives contain an implicit agent while non-causatives do not. Crucially, there are some non-causative verbs that appear with an agentive causer in Udmurt:

(10) a. ?Pinaljos anaj-lesh sajka-zy.

child.PL.NOM mother-ABL wake.up-PAST.3SG

'The children were woken up by the mother.'

(Lit.: 'The children woke up from the mother.') 
b. Vaza pyli-s'k-iz Sasha seren. vase.NOM break-ERG-PAST.3SG Sasha.NOM by

'The vase was broken by Sasha.'

(Lit.: 'The vase broke by Sasha.')

c. Ös ushkti-s'k-iz Sasha seren.

door.NOM open-ERG-PAST.3SG Sasha.NOM by

'The door was opened by Sasha.'

(Lit.: 'The door opened by Sasha.')

It is important to note again that unlike non-agentive causers and causing events, the agentive causer can only appear with non-causative verbs that belong to the anticausative type (see section 2.1.2) and it is only marginally well-formed with causative types. I come back to this issue in section 5 .

\subsubsection{Causative verbs}

Causative verbs have a causer argument. This can be an agent (11a), a non-agentive causer (11b) or a causing event (11c).

(11) a. Anaj sajka-t-iz pinaljosty. agent mother.NOM wake.up-CAUS-PAST.3SG child.PL.ACC

'The mother woke up the children.'

b. Gudyrjaskem sajka-t-iz pinaljosty. non-agent thunder.NOM wake.up-CAUS-PAST.3SG child.PL.ACC

'The thunder woke up the children.'

c. Anaj-atajlen kopaskemez sajka-t-iz pinaljosty.

father-mother.GEN fight.ACC wake.up-CAUS-PAST.3SG child.PL.ACC

'The fight of the parents woke up the children.' causing event

The appearance of the causer and the theme arguments is obligatory regardless of the type of the causative verb.

\section{The valence-change markers}

Udmurt has two important valence-changing suffixes: the so-called reflexive suffix $-s^{\prime} k$ - and the causative suffix - $t$-. As shown in the examples above, both have an important role in the causative/non-causative alternation. The non-causative variant - if marked - is always marked by $-s^{\prime} k$-, while the causative variant is marked by the morpheme $-t-$, as we have seen in example (6) repeated below as (12). 
(12) a. Kar umoj azyn-s'k-e.

city.NOM good develop-ERG-PRES.3SG

'The city develops well.'

b. Kivaltis' programmajez azyn-t-iz.

director.NOM program.ACC develop-CAUS-PAST.3SG

'The director developed the program.'

\subsection{The function of the $-t$ - marker}

As argued above, the morpheme -t- marks the causative variant of the alternation. However, it has two further important functions as well.

1. Productive causative marker. It was shown in example (2) repeated below as (13) that the morpheme - $t$ - is the productive causative marker in Udmurt.

(13) a. Sasha gozhtetez gozht-iz.

Sasha.NOM letter.ACC write-PAST.3SG

'Sasha wrote the letter.'

b. Sasha Mashajez gozhtetez gozhte-t-iz.

Sasha.NOM Masha.ACC letter.ACC write-CAUS-PAST.3SG

'Sasha made Masha write the letter.'

As a productive causative marker, $-t$ - projects its own Cause head in the syntactic structure. This is illustrated in (14). ${ }^{8}$

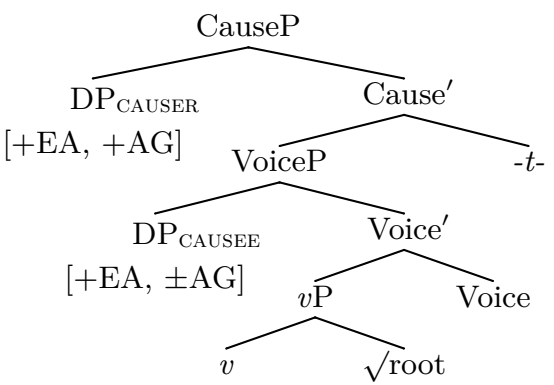

${ }^{8}$ In this paper, I follow Pylkkanen's (2002; 2008) analysis of the causative construction. Pylkkänen $(2002 ; 2008)$ argues for separate positions for the agent argument and for the causer argument. In the case of morphological causatives the causative projects its own projection (CauseP). The Cause head is similar to $v_{\mathrm{CAUSE}}$ in Harley's (1995) proposal. For a detailed explanation, see Pylkkänen (2002; 2008). 
The Cause head selects a Voice $\mathrm{P}^{9}$ that introduces the external argument. This argument functions as the Causee and it has either a [+agentivity] or a [-agentivity] feature. The Causer argument, on the other hand, sits in the specifier position of the CauseP and only bears a [+agentivity] feature.

2. Verbalizer. It was shown in example (3) repeated below as (15) that the morpheme - $t$ - also functions as verbalizer in Udmurt.

(15) a. Sasha vamysh ljog-iz.

Sasha.NOM step.NOM make-PAST.3SG

'Sasha took a step.'

b. Sasha vamysh-t-iz.

Sasha.NOM take.a.step-VERB-PAST.3SG

'Sasha took a step.'

As is shown in the example in (15) the morpheme -t- is responsible for the verbal category in the sense of Arad (2005), and syntactically it sits in the head position of the verbal projection.

\subsection{The functions of the $-s^{\prime} k$ - marker}

In addition to serving as the non-causative marker (see the previous section), the morpheme $-s^{\prime} k$ - has other functions, too. According to Kozmács (2008), this morpheme has at least four different derivational functions in the grammar.

1. It creates verbs with an implicit object:

(16) a. Pisej aste achiz korma- $\emptyset$.

kitty.NOM self.NOM self.ACC scratch-PRES.3SG

'The kitty scratches itself.'

b. Pisej korma-s'k-e.

kitty.NOM scratch.oneself-ERG-PRES.3SG

'The kitty scratches itself.'

(Kozmács 2008, 153)

The argument structure of the verbs in $(16 \mathrm{a}-\mathrm{b})$ contains an agent and a theme, and both arguments are obligatory. However, while in the argument structure of the verb in (16a) the agent and the theme do not have to be coreferent with each other, in (16b) the implicit theme has to be coreferent with the agent, and so it does not need to be visible.

${ }^{9}$ Kratzer's Voice head is called little $\boldsymbol{v}$ in Chomsky's (1995) proposal. 
2. It creates unergative verbs:

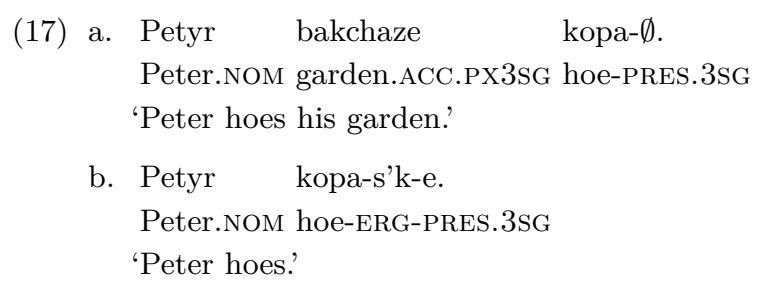

(ibid., 154)

In (17a) the verb kopany 'to hoe' is a transitive verb with an agent and a theme argument. The verb kopas'kyny 'to hoe', on the other hand, is an intransitive-unergative verb with no theme argument. Similarly to the verb kormas'kyny 'to scratch' in (16b), kopas'kyny 'to hoe' prohibits the appearance of the theme argument. Unlike in (16b), there is no implicit object in the sentence. The direct object of the transitive variant can (but does not have to) occur in the sentence as a locative adjunct (18).

(18) Petyr bakchayn kopa-s'k-e.

Peter.NOM garden.INESS hoe-ERG-PRES.3SG

'Peter hoes in the garden.'

(idem.)

3. It creates unaccusative verbs:

(19) a. Soje todmo vrach emja- $\emptyset$.

he.ACC known doctor.NOM cure-PRES.3SG

'It is a known doctor, who cures him.'

b. So todmo vrach doryn emja-s'k-e.

he.NOM known doctor.NOM at heal-ERG-PRES.3SG

'It is at the known doctor, where he heals.'

(ibid., 153)

The "surface" subject of unaccusative verbs is the "deep" object (Levin \& Rappaport Hovav 1995, henceforth: L\&R-H 1995). This can be seen in (19a) and (19b), emjany 'to cure' has an agent and a patient argument. However, in (19b) which contains the verb emjas'kyny 'to heal', only the patient of (19a) may appear, while the agent vrach 'doctor' is not allowed. 
4. Passivization: ${ }^{10}$

(20) Soku kyk choshen busyyn luozy: odigez bas'ti-s'k-oz,

then two together.INSTR field.INESS be.FUT.3PL one.DET take-ERG-FUT.3SG

nosh muketyz kel'ti-s'k-oz.

and other.DET leave-ERG-FUT.3SG

'Then two men will be in the field: one will be taken and the other left.'11

(Matthew 24,40; Kozmács 2008, 159)

Passivization with $-s^{\prime} k$ - is very common in the text of the Bible (see (20), which is a sentence from the new translation of the Gospel by Matthew). In the Udmurt passive sentence either the agent remains unexpressed or it appears with the postposition pyr 'by'.

As we have seen, the $-s^{\prime} k$ - morpheme has different functions in Udmurt. The following assumption suggests itself: the different functions of the morpheme can be traced back to one basic function, namely the reduction of the theme argument.

\section{Distinguishing passives from non-causatives}

Before turning to the decomposition of the verbs taking part in the causative alternation, the passive forms of the transitive verbs need to be distinguished from their non-causative counterparts. What passive and non-causative verbs have in common is the lack of an external argument. This contrasts with the properties of transitive verbs derived from the same root. However, the difference relates to the presence of agentive features only in the former case (Alexiadou et al. 2006). This similarity is reflected by the empirical fact that there are languages where the passive marker can function as the non-causative marker as well. Traditionally, the difference is explained by the reduction of the arguments, since in the passive form of the transitive verb there is no explicit agent, as opposed to non-causative verbs, where there is no agent or causer at all. According to Alexiadou et al. (2006), the difference between passives and non-causatives

10 The most common suffix of passivization in Udmurt is the -(e)myn participial marker:

(i) So zale pydloges intyja-myn.

it hall.ILL back place-PASS

'It is placed to the back into the hall.' $\quad$ (Kozmács 2008, 163)

11 The English translation is from the New King James Version. 
depends on the properties of the Voice head introducing the agent, and its combinations with the causer introduced by the Cause head and various types of roots.

This difference between passives and non-causative verbs has been studied extensively in languages like English (e.g., Manzini 1983; Marantz 1984; Reinhart 2000; Schäfer 2008, among many others).

There are two differences between these types of verbs: (i) modification or control, and (ii) verb restrictions.

As far as modification is concerned, passives can be modified by (i) byphrases (21a), (ii) agent-oriented adverbs (21b), and (iii) they allow control into purpose clauses (21c). Non-causatives do not share any of these properties $(21 d-f)$ :

(21) a. The boat was sunk by Bill.

b. The boat was sunk on purpose.

c. The boat was sunk to collect the insurance.

d. *The boat sank by Bill.

e. ${ }^{*}$ The boat sank on purpose.

f. *The boat sank to collect the insurance.

(Schäfer 2008, 116)

As for Verb Restriction, all transitive verbs have a passive counterpart, but not all of them have a non-causative variant (22a-f).

(22) a. The baker cut the bread.

b. The bread was cut by the baker.

c. ${ }^{*}$ The bread cut.

d. Bill broke the glass.

e. The glass was broken by Bill.

f. The glass broke.

(idem.)

L\&R-H (1995) argue that in addition to Verb Restriction there is also Selectional Restriction: intransitive verbs taking part in the alternation have a selectional restriction on their internal arguments. This restriction can be formulated as follows (L\&R-H 1995; Reinhart 2000; 2002):

(23) The transitive verbs that cannot form anticausatives restrict their subjects to agents or agents and instruments and disallow causers. ${ }^{12}$

(L\&R-H 1995, 106)

12 Since the causer argument does not need to be agentive, distinguishing between the causer and the agent argument is necessary. 
In Udmurt, two suffixes, $-s ' k$ - and -emyn, can be used as passive markers $(24 \mathrm{a}-\mathrm{b}) .^{13}$

(24) a. Sasha jyrs'ize kvas't-iz.

Sasha.NOM hair.ACC dry-PAST.3SG

'Sasha dried his hair.'

b. Jyrs'i kvas'ti-s'k-iz.

hair.NOM dry-ERG-PAST.3SG

'The hair was dried.'

c. Jyrs'i kvas't-emyn.

hair.NOM dry-PASS

'The hair was dried'

The sentences in $(24 \mathrm{~b}-\mathrm{c})$ are both passive variants of the active sentence in (24a). The agent is optional in them; if it does appear, then it bears an INSTR marker:

(25) a. Jyrs'i kvas'ti-s'k-iz Sashaen.

hair.NOM dry-ERG-PAST.3SG Sasha.INSTR

'The hair was dried by Sasha.'

b. Jyrs'i kvas't-emyn Sashaen.

hair.NOM dry-PASS Sasha.INSTR

'The hair was dried by Sasha.'

INSTR case is used as an agent marker only in passives; it never occurs with non-causatives:

(26) a. Jyrs'i kvasti-s'k-iz Sashaen. passive hair.NOM dry-ERG-PAST.3SG Sasha.INSTR

'The hair was dried by Sasha.'

b. ${ }^{*}$ Jyrs'i kvasti-s'k-iz Sashaen. ${ }^{14}$ non-causative hair.NOM dry-ERG-PAST.3SG Sasha.InSTR

'*The hair dried by Sasha.'

13 There is a morphological difference between the two markers; - $s$ ' $k$ - is an affix and it can function as a passive marker only with the 3rd person marker attached to it. The morpheme -emyn, on the other hand, is a suffix and it is used without person markers. Historically, -emyn can be decomposed into the -em participle ending and the -yn inessive case marker.

14 To clarify the difference between the two sentences with the same word-formation $k v a s t i-s$ ' $k$-iz two different contexts were used. In the first context only the passive 
The ability of the verb to control into purpose clauses is also a good test to tease apart passives and non-causative verb-formations. Evidence for the hidden agentivity of passives comes from the fact that they can be modified by purpose clauses (27).

(27) a. Jyrs'i kvas'ti-s'k-iz med vyl' jyrs'i oktet les'toz.

hair.NOM dry-ERG-PAST.3sG part new hair.NOM style make.FUT.3GS

'The hair was dried to make a new hairstyle.'

b. Jyrs'i kvas't-emyn med vyl' jyrs'i oktet les'toz.

hair.NOM dry-PASS part new hair.NOM style make.FUT.3GS

'The hair was dried to make a new hairstyle.'

This type of modification is not possible with non-causative verbs (28).

(28) *Jyrs'i kvas'ti-s'k-iz med vyl' jyrs'i oktet les'toz.

hair.NOM dry-PASS-PAST.3SG part new hair.NOM style make.FUT.3GS

'*The hair dried to make a new hairstyle.'

The fact that agents are licensed in passives but not in non-causatives suggests that the difference between the two has to do with agentivity, thus agentivity and causation should be syntactically represented by distinct functional heads (see also Pylkkänen 2002; Alexiadou et al. 2006). The syntactic structure of Udmurt passive forms marked by -emyn or $-s^{\prime} k$ contains a Voice head in the sense of Kratzer (1994); this head hosts the agent argument. The structure of passives is modeled in (29):

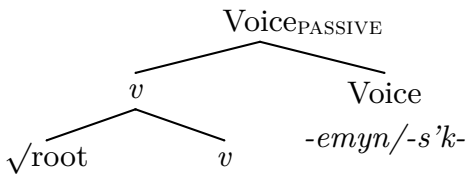

\section{Analyzing the alternation}

The main proposal in this section draws on work by Alexiadou (2010; Alexiadou et al. 2006), and others: bare and morphologically marked causative and non-causative verbs have the same structure. Alexiadou et al. (2006), modifying Kratzer (2003), assume the following core syntactic structure for all types of change of state verbs, causatives, non-causatives and passives (30).

variant could be interpreted as a correct answer and in the second context only the non-causative variant. (I thank the reviewers for pointing this out.) 
(30) [ (Voice) [ CAUS/v [ Root + Theme ]]]

The structure is built on a category-neutral root which is merged either with a verbalizer head (v) or a causative-verbalizer head (CAUS). Voice is a lexical head that introduces the external argument for any predicate (see Kratzer 1996; 2003) and merges with a vP/CAUSP layer.

\subsection{Non-causative verbs}

As was illustrated by (1a) and (4a), repeated below as (31a-b), noncausative verbs have the following two types.

(31) a. Pinaljos sajka-zy.

child.PL.NOM wake.up-PAST.3PL

'The children woke up.'

b. Vaza pyly-s'k-iz.

vase.NOM break-ERG-PAST.3SG

'The vase broke.'

In (31a) the non-causative verb does not contains the morpheme $-s^{\prime} k$-. In (31b), on the other hand, the ergative morpheme $-s^{\prime} k$ - occurs in the verb.

As observed in subsection 2.2.1, non-causative verbs can be divided into two groups on the basis of whether they allow the optional causer to appear. Non-causative verbs without the causative/transitive morpheme -t- cannot appear with the agentive causer. This contrasts with noncausative verbs with -t-, for instance $u s h-t i-s$ ' $k$ - $i z$ 'to open' in (32c), which can co-occur with an agentive causer. Consider the examples in (10), repeated below as (32).

(32) a. 'Pinaljos anaj-lesh sajka-zy.

child.PL.NOM mother-ABL wake.up-PAST.3SG

'The children were woken up by the mother.'

(Lit.: 'The children woke from the mother.')

b. Vaza pyli-s'k-iz Sasha seren.

vase.NOM break-ERG-PAST.3SG Sasha.NOM by

'The vase was broken by Sasha.'

(Lit.: 'The vase broke by Sasha.')

c. Ös ush-ti-s'k-iz Sasha seren.

door.NOM open-ERG-PAST.3SG Sasha.NOM by

'The door was opened by Sasha.'

(Lit.: 'The door opened by Sasha.') 
Based on the empirical data, I propose that non-causative verbs have two different structures $(33 \mathrm{a}-\mathrm{b})$.

(33) a.

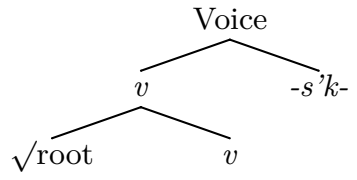

b.

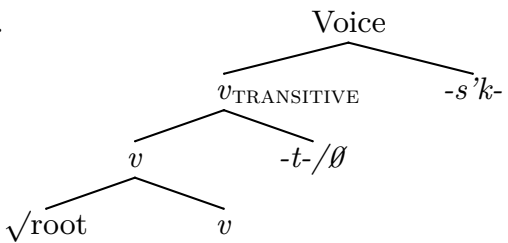

I suggest that non-causative verbs that cannot appear with an agentive causer (e.g., sajkany 'to wake up') have the structure in (33a). Those that can appear with an agentive causer have the structure in (33b). These verbs have an extra layer, and this layer is responsible for the agentivity of the causer.

\subsection{Causative verbs}

As observed above, causative verbs can be divided into two groups on the basis of whether they contain the morpheme $-t$ - or not. Consider the examples in (1b) and (4b) repeated below as (34).

(34) a. Anaj pinaljoszy sajka-t-iz.

mother.NOM child.PL.ACC wake.up-CAUS-PAST.3SG

'The mother woke up the children.'

b. Sasha vazajez pyl-iz.

Sasha.NOM vase.ACC break-PAST.3SG

'Sasha broke the vase.'

In spite of this fact, however, all causative verbs have the same argument structure, and the causer can be: (i) an agent, (ii) a causing event, and (iii) a non-agentive causer. Based on these properties, I propose the following syntactic structure for the causative variants of the alternation (35).

(35) a. $\sqrt{ }$ root $+\mathrm{v}+$ Cause

b.<smiles>[Mg]C=CC=[Te]</smiles>

Unlike non-causative verbs, causative verbs are associated with a Cause head that hosts the causer argument of the verb. The Causer argument 
is not necessarily agentive. This means that the Causer that sits in [spec, CauseP] can have either a [+Agentivity] or a [-Agentivity ] feature.

\section{Conclusion}

In this paper I discussed new empirical data of the causative/non-causative alternation in Udmurt.

In my proposal, the alternation takes place in the syntax rather than in the lexicon. Using the framework of Distributed Morphology (Marantz 1984; Arad 2005), I suggested that both causative and non-causative verbs are derived from roots in the course of Narrow Syntax.

Causative verbs contain either the overt causative morpheme $-t$ - or a phonologically null suffix, while non-causative verbs can have a phonetically null suffix or the ergative morpheme $-s^{\prime} k$ -

The syntactic structures of the alternants differ in size: causative verbs contain an extra layer, the CauseP, which introduces the causer argument. As argued in the paper, the Causer is not necessarily agentive, and so the Cause head attached to the $\mathrm{vP}$ can bear either the [-Agentivity] or the [+Agentivity] feature. The structure of non-causative verbs lacks the Cause layer; it contains only the verbalizer layer and VoiceP (the latter introduces the external argument).

Interestingly, some non-causative verbs allow an agentive causer (a property that has not been observed for non-causatives cross-linguistically). I suggested that the structure of these verbs contains an extra layer that can host the agent causer.

\section{References}

Alexiadou, Artemis. 2010. On the morpho-syntax of (anti-)causative verbs. In M. Rappaport Hovav, E. Doron and I. Sichel (eds.) Lexical semantics, syntax, and event structure. Oxford: Oxford University Press. 177-203.

Alexiadou, Artemis, Elena Anagnostopoulou and Florian Schäfer. 2006. The properties of anticausatives crosslinguistically. In M. Frascarelli (ed.) Phases of interpretation. Berlin \& New York: Mouton de Gruyter. 187-21.

Arad, Maya. 2005. Roots and patterns: Hebrew morpho-syntax. Dordrecht: Springer.

Chomsky, Noam. 1995. The minimalist program. Cambridge, MA: MIT Press.

Harley, Heidi B. 1995. Subjects, events, and licensing. Doctoral dissertation. MIT.

Haspelmath, Martin. 1993. More on the typology of inchoative/causative verb alternations. In B. Comrie and M. Polinsky (eds.) Causatives and transitivity. Amsterdam \& Philadelphia: John Benjamins. 87-120. 
Kozmács, István. 2004. Adalékok az antikauzatív/inchoatív igepárok tipológiájához az udmurt alapján [Data to the typology of anticausative/inchoative verb pairs on the basis of Udmurt]. In E. Mészáros, S. Szeverényi and B. Wagner-Nagy (eds.) Mikola-konferencia 2002. Szeged: SzTE Finnugor Tanszék. 85-90.

Kozmács, István. 2008. Az -s’k- képző az udmurt (votják) igeképzés rendszerében [The suffix $-s^{\prime} k$ - in the system of Udmurt word-formation]. Doctoral dissertation. University of Nyitra.

Kratzer, Angelika. 1994. On external arguments. In E. E. Benedicto and J. T. Runner (eds.) Functional projections (University of Massachusetts Occasional Papers in Linguistics 17). Amherst: University of Massachusetts, GLSA. 103-129.

Kratzer, Angelika. 1996. Severing the external argument from its verb. In J. Rooryck and L. Zaring (eds.) Phrase structure and the lexicon. Dordrecht: Kluwer. 109-137.

Kratzer, Angelika. 2003. The event argument and the semantics of verbs. http://semanticsarchive.net/Archive/GU1NWM4Z/ (30.06.2014).

Levin, Beth and Malka Rappaport Hovav. 1995. Unaccusativity. At the syntax-lexical semantics interface. Cambridge, MA: MIT Press.

Manzini, M. Rita. 1983. On control and Control Theory. Linguistic Inquiry 14. 421-446.

Marantz, Alec. 1984. On the nature of grammatical relations. Cambridge, MA: MIT Press.

Marantz, Alec. 1997. No escape from syntax: Don't try morphological analysis in the privacy of your own lexicon. University of Pennsylvania Working Papers in Linguistics 4. 201-225.

Nedyalkov, Vladimir P. and Georgij G. Silnitsky. 1973. The typology of morphological and lexical causatives. In F. Kiefer (ed.) Trends in Soviet theoretical linguistics. Dordrecht: D. Reidel. 1-32.

Pylkkänen, Liina. 2002. Introducing arguments. Doctoral dissertation. Massachusetts Institute of Technology.

Pylkkänen, Liina. 2008. Introducing arguments. Cambridge, MA: MIT Press.

Reinhart, Tanya. 2000. The Theta System: Syntactic realization of verbal concepts (OTS Working Papers in Linguistics). Utrecht: Utrecht Institute of Linguistics OTS.

Reinhart, Tanya. 2002. The Theta System: An overview. Theoretical Linguistics 28. 229-290.

Salánki, Zsuzsanna. 2007. Az udmurt nyelv mai helyzete [On the current state of the Udmurt language]. Doctoral dissertation. ELTE, Budapest.

Schäfer, Florian. 2008. The syntax of (anti-)causatives: External arguments in changeof-state contexts. Amsterdam \& Philadelphia: John Benjamins.

Tánczos, Orsolya. 2013. A syntactic approach to Udmurt causatives. Bucharest Working Papers in Linguistics 15. 61-76. 